\title{
Viscoelastic characterization of an EPDM rubber and finite element simulation of its dry rolling friction
}

\author{
D. Felhös ${ }^{1 *}$, D. Xu1 , A. K. Schlarb ${ }^{1}, K$. Váradi², T. Goda ${ }^{3}$ \\ ${ }^{1}$ Institut für Verbundwerkstoffe GmbH (Institute for Composite Materials), University of Kaiserslautern, \\ D-67663 Kaiserslautern, Germany \\ 2Department of Machine and Product Design Budapest University of Technology and Economics H-1111, \\ Múegyetem rkp.3, Budapest, Hungary \\ ${ }^{3}$ Institute of Mechanical Engineering and Safety Techniques, Bánki Donát Faculty of Mechanical Engineering, \\ Budapest Tech, H-1081 Budapest, Népszínház u. 8, Hungary
}

Received 30 October 2007; accepted in revised form 12 January 2008

\begin{abstract}
The viscoelastic properties of an ethylene/propylene/diene rubber (EPDM) containing 30 parts per hundred parts rubber $[\mathrm{phr}]$ carbon black (CB) were determined by dynamic mechanical thermal analysis (DMTA) measurements. A 15term Maxwell-model was created to describe the time-dependent material behavior of this rubber. The frictional behavior under dry rolling conditions was studied on a home-built rolling ball (steel)-on-plate (rubber) (RBOP) test rig. Both normal and tangential forces were detected during the measurements. The rolling test was simulated with the MSC.Marc finite element (FE) software using the evaluated viscoelastic material properties. Results of the experimental tests and of the simulation were compared and a good agreement was found between them.
\end{abstract}

Keywords: modeling and simulation, rubber, viscoelasticity, finite element method (FEM), rolling friction

\section{Introduction}

Rubbers are utilized widely in mechanical engineering. Tires, v-belts, belts, rollers are made of rubbers or of rubber-based composite materials. The water-, heat- and chemical-resistances, the excellent and tailorable elastic properties, the high coefficient of friction make them as first-choice materials for the above applications. However the construction and design of the related rubber parts need profound knowledge on the non-linear and viscoelastic properties of the related rubbers. The internal damping of rubbers can be useful, but the same phenomenon can cause unfavorable energy dissipation during rolling or cyclic fatigue-type loading of rubbery elements.

The exact analytical calculation of the observed strains during mechanical loading of rubbery ele- ments is a great challenge due to the complexity of the viscoelastic material models. Although some simplified analytical methods were developed to evaluate for example the friction resistance or internal heat generation in viscoelastic materials during rolling contact, they failed for more complex stress states or for repeated stresses [1-9]. On the other hand the finite element (FE) method is able to handle complex viscoelastic material models owing to the permanent advancement of the software and hardware background. This progress makes possible to perform more complex and at the same time, accurate simulations [10-12].

The aim of this study was to investigate the rolling friction whereby a steel ball is rolling on a rubber plate. 
The linear-viscoelastic properties of the rubber were determined by dynamic mechanical thermal analysis (DMTA). On the basis of DMTA measurements a master curve was created and a 15-term Maxwell-model was fitted to this master curve. To describe the incompressibility and the non-linear behavior of the rubber, i.e. the non-linear stressstrain curve, the Mooney-Rivlin material model was used. The constants of the two term MooneyRivlin material law were calculated by simplified equations [20-21].

For the simulations the FE software MSC.Marc was used.

The rolling friction of an ethylene/propylene/diene rubber (EPDM) was measured in an oscillating rolling ball (steel)-on-plate (rubber) configuration (Oscillating-RBOP) and simulated by FEM. Friction force, normal load and coefficient of friction (COF) were determined. The results of the tests and the simulations were compared with each other and discussed.

\section{Experimental}

\subsection{Rolling friction test}

Rolling friction tests were carried out on a home built test rig with oscillating rolling ball $(100 \mathrm{Cr} 6$, $d=2 r=14 \mathrm{~mm}, R_{a}=1 \mu \mathrm{m}$ ) and stationary rubber plate (cf. Figure 1). The steel ball is driven by the
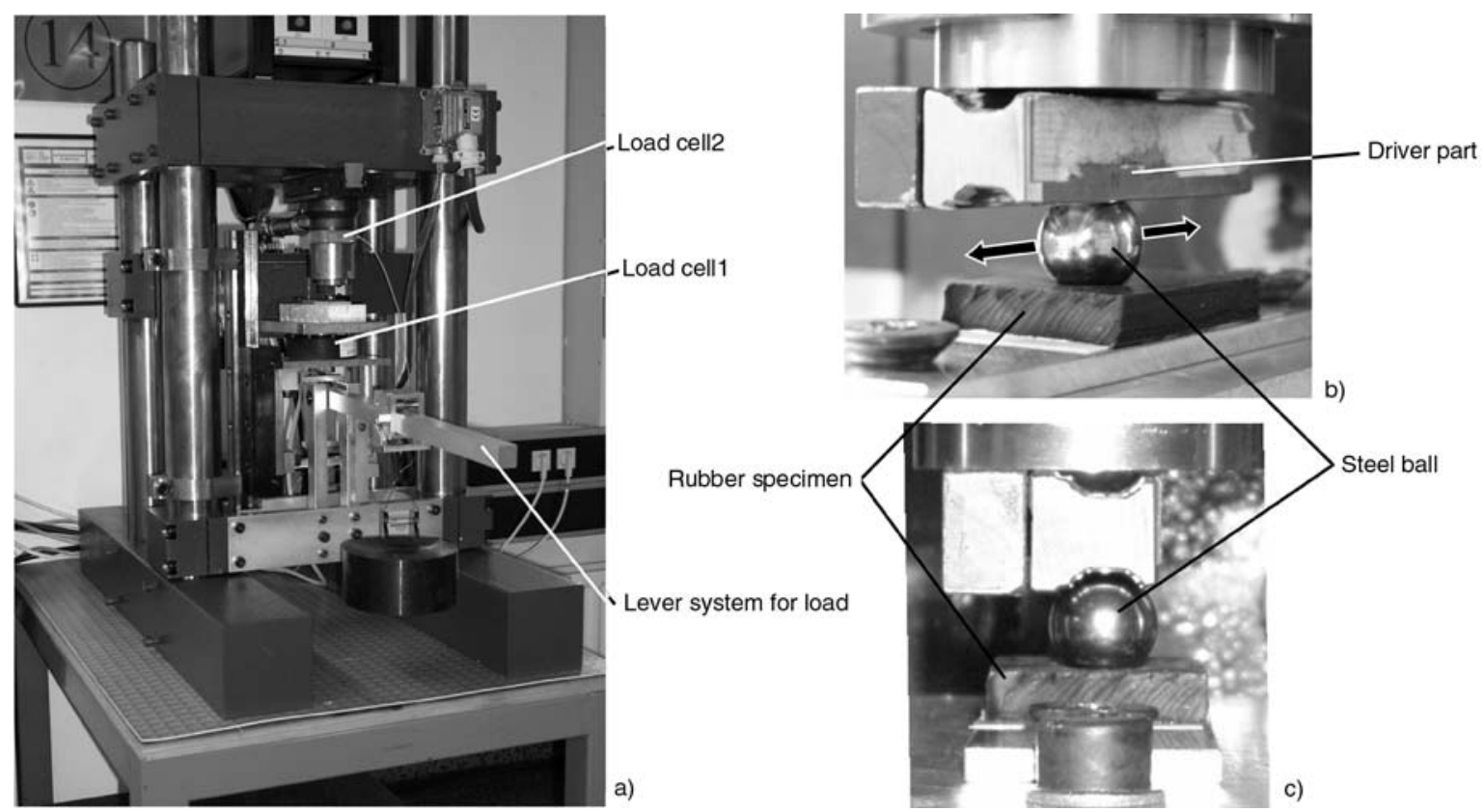

Figure 1. Overview of the Oscillating-RBOP machine (a), detailed view of steel ball rolling on a flat rubber specimen (b), front view of the set-up (c) 
guiding groove on the driver part $(8.6 \mathrm{~mm}), h$ is the vertical distance from the center point to the upper contact point of the ball, calculated by Equations (1) and (2):

$h=r \cdot \cos \alpha$

where

$$
\alpha=\arcsin \frac{g}{2 \cdot r} .
$$

We assumed the pure rolling of the ball without any slip at the contact both with the driver part and with the rubber specimen. With this assumption the position and the velocity of the driver part could be calculated using Equations (3) and (4):

$$
\begin{aligned}
& s_{D}(t)=-A \cdot \cos \left(\frac{2 \pi}{T} \cdot t\right) \\
& v_{D}(t)=\frac{2 \pi}{T} \cdot A \cdot \sin \left(\frac{2 \pi}{T} \cdot t\right)
\end{aligned}
$$

The ratio of the driver part's displacement and velocity to those of the rolling ball is constant. The displacement $(s(t))$ and the velocity $(v(t))$ of the rolling ball is smaller than that of the driver part. This ratio is given by the Equation (5):

$$
\frac{s(t)}{s_{D}(t)}=\frac{v(t)}{v_{D}(t)}=\frac{r}{r+h}
$$

Using Equations (3), (4) and (5), the displacement and the speed of the rolling ball can be described by Equations (6) and (7):

$$
\begin{aligned}
& s(t)=-A \cdot\left(\frac{r}{r+h}\right) \cos \left(\frac{2 \pi}{T} \cdot t\right) \\
& v(t)=\frac{2 \pi}{T} \cdot A \cdot\left(\frac{r}{r+h}\right) \sin \left(\frac{2 \pi}{T} \cdot t\right)
\end{aligned}
$$

The maximum of the displacement $\left(s(t)_{\max }\right)$ of the rolling ball means the amplitude of the reciprocating motion. This will be reached at $t=0, t=T / 2$ and $t=T$. The maximum of the rolling velocity is reached at $t=T / 4$ and $t=3 T / 4$ (cf. Figure 2). Substituting the data into Equations (6) and (7), the displacement and the velocity of the rolling ball can be described by Equations (8) and (9):

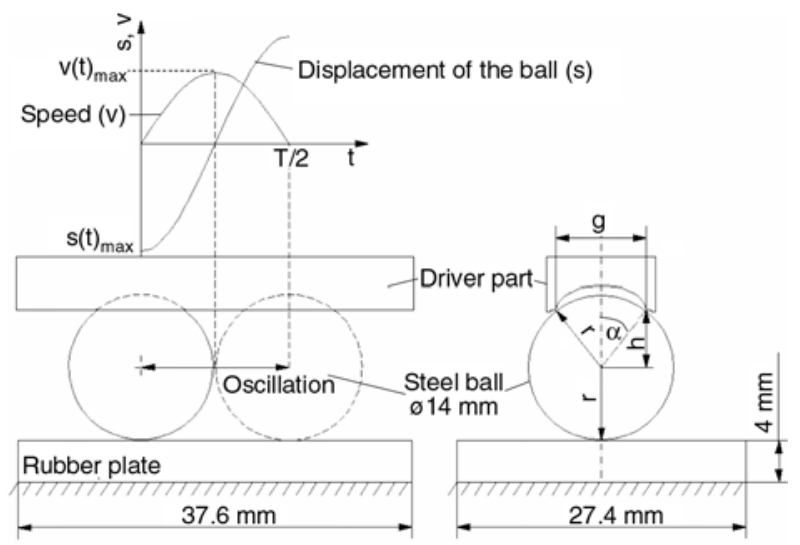

Figure 2. Schematic sketches of the contact geometry and of the ball's kinematics in a half cycle

$s(t)=-0.007019 \cdot \cos \left(\frac{2 \pi}{T} \cdot t\right) \quad[\mathrm{m}]$

$v(t)=-0.00147 \cdot \sin \left(\frac{2 \pi}{T} \cdot t\right) \quad\left[\frac{\mathrm{m}}{\mathrm{s}}\right]$

If we fixed the center point of the coordinate system at the middle point of the ball, the apparent angular velocity of the ball $(\omega(t))$ could be calculated as Equation (10):

$\omega(t)=\frac{v(t)}{r}$

This value will be needed later by the description of the boundary conditions of the FE simulation.

\subsubsection{Results of the rolling frictiontest}

During the measurement the normal and the tangential force were registered (cf. Figure 3). It shows the change of the normal and tangential forces in one cycle and the calculated coefficient of

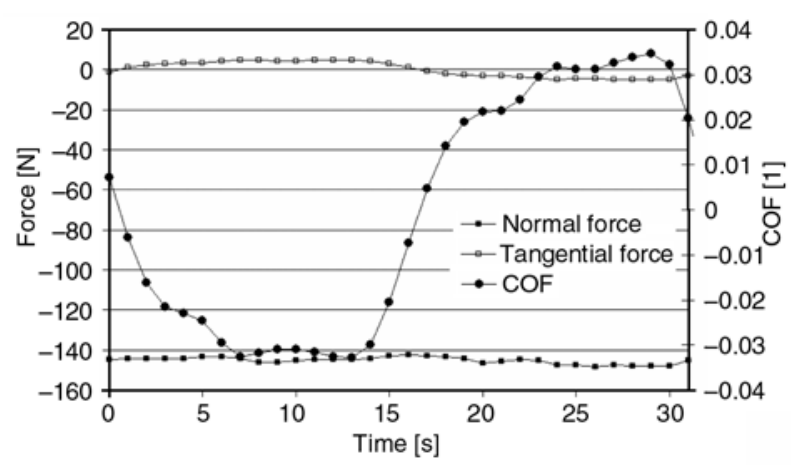

Figure 3. Change of the normal- and tangential forces vs. the time in one cycle and the change of the calculated coefficient of friction (COF) 
friction $(\mathrm{COF})$. The $\mathrm{COF}$ is calculated as the ratio of the friction force to the normal load (Equation (11)):

$$
\mathrm{COF}=\frac{F_{T}}{F_{N}}
$$

where $F_{T}$ is the tangential force, $F_{N}$ is the normal force.

The sign of the friction force is changing, due to the changing rolling direction. The normal force is constant; however a small deviation was observed at the end of the cycle. The highest and smallest values of the tangential force are approximately $\pm 4.8 \mathrm{~N}$. Between the direction changes of the rolling ball a plateau can be seen in the tangential force vs. time curve. The COF vs. time curve has also an oscillation, the maximal and minimal value of it are approximately +0.034 as well as -0.034 .

\subsection{Material characteristics}

An EPDM rubber, containing 30 parts per hundred parts rubber [phr] carbon black (CB) was investigated in this study. The investigated EPDM stock was prepared in a laboratory internal mixer and the curatives were introduced on a laboratory open mill. The recipe used was as follows: EPDM (Keltan ${ }^{\circledR} 512$ of DSM Elastomers, Sittard, The Netherlands): 100 parts; carbon black (N550): 30 parts; ZnO: 5 parts; stearic acid: 1 part, sulfur: 1.5 parts, N-cyclohexyl-2-benzothiazole sulfenamide (CBS, Vulkacit CZ of Bayer, Leverkusen, Germany): 0.6 part; 2-mercapto benzothiazole (MBT, Vulkacit Mercapto by Bayer): 0.6 part; zinc dibenzyl dithiocarbamate (Rhenogran ZBEC-70 of Rhein Chemie): 1.5 parts and zinc dicyanatodiamine (Rhenogran Geniplex 80 of Rhein Chemie, Mannheim, Germany): 0.6 part. Rubber sheets (ca. 2 and $4 \mathrm{~mm}$ thick) were produced by compression molding at $160^{\circ} \mathrm{C}$ and $7 \mathrm{MPa}$ pressure using a Satim press (Rion des Landes, France). The vulcanization time was adjusted by considering the time needed for the $90 \%$ crosslinking at $T=160^{\circ} \mathrm{C}$. The material characteristics were determined in the Institut für Verbundwerkstoffe (IVW) [13].

To be able to simulate the rolling friction of the rubber specimen, it is inevitable to determine the viscoelastic properties of the investigated material. Usually a dynamic mechanical thermal analysis

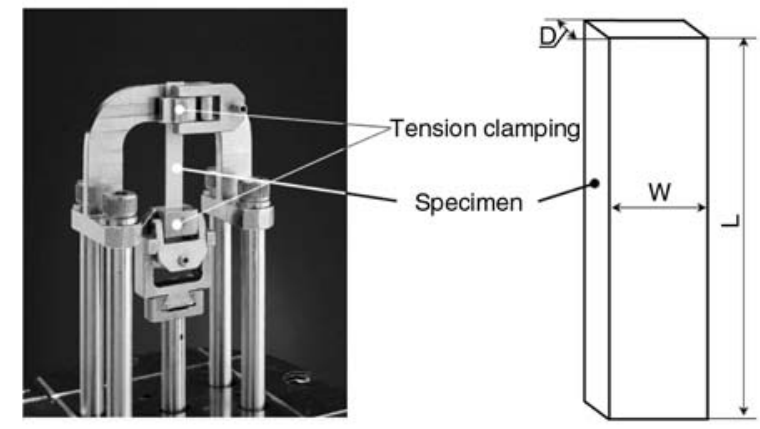

Figure 4. Picture of the tension grip with the specimen. Note: The specimen dimension is the following: $W=10 \mathrm{~mm}, L=20 \mathrm{~mm}, D \approx 2 \mathrm{~mm}$

(DMTA) test is carried out [14] where the frequency of the applied stress or strain and the temperature are changed in parallel. Another method is the stress relaxation measurement where a constant strain is applied on the specimen and the reaction force is detected as a function of the time. This measurement is repeated at different temperatures in a wide temperature range.

In our case the DMTA spectra was recorded on rectangular specimens (length $\times$ width $\times$ thickness $=$ $20 \times 10 \times$ ca. $2 \mathrm{~mm}^{3}$ ) in tensile mode (cf. Figure 4) as a function of temperature (from -100 to $+100^{\circ} \mathrm{C}$ ) and frequency at 1,10 and $100 \mathrm{~Hz}$ using a Q800 device of TA Instruments (New Castle, DE, USA). The conditions set were: strain $0.01 \%$, temperature step: $5^{\circ} \mathrm{C}$, time for temperature equilibration at each step: $3 \mathrm{sec}$. According to the user's manual of the DMTA device, the storage $\left(E^{\prime}\right)-$, the loss moduli $\left(E^{\prime \prime}\right)$ and the loss factor $(\tan \delta)$ were calculated using Equations (12), (13) and (14):

$E^{\prime}=E^{*} \cdot \cos \delta$

$E^{\prime \prime}=E^{*} \cdot \sin \delta$

$\operatorname{tg} \delta=\frac{E^{\prime \prime}}{E^{\prime}}$

where, $E^{*}$ is the measured complex moduli of the sample and $\delta$ is the phase angle which is calculated by Equation (15):

$\delta=2 \pi \cdot f \cdot \Delta t$

where $f$ is the frequency of the dynamic excitation and $\Delta t$ is the time delay between stress and strain. 


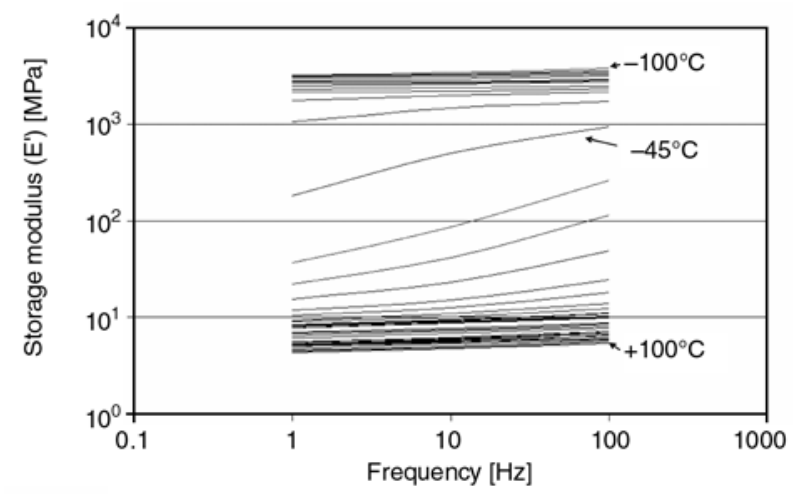

Figure 5. Storage modulus curves at different temperatures

As a result of the DMTA measurements, one can get the change of the storage $\left(E^{\prime}\right)-$, and of the loss moduli $\left(E^{\prime \prime}\right)$ as well as of the loss factor $(\tan \delta)$ versus the applied frequency and versus the temperature. Figure 5 illustrates the change of the storage moduli $\left(E^{\prime}\right)$ versus the frequency at different temperatures. In the figure, one can see that the highest moduli are measured at the lowest temperature, while the lowest moduli were measured at the highest temperature. The glass transition temperature $\left(T_{g}\right)$ can be clearly seen $\left(-45^{\circ} \mathrm{C}\right.$, cf. Figure 5$)$, because the variation of the storage modulus is most intensive at $T_{g}$. The noteworthy temperatures are shown by arrows in Figure 5.

From the storage moduli curves, based on the Williams-Landel-Ferry (WLF) equation, we were able to create a storage modulus master curve (cf. Figure 6) [15]. The reference temperature was chosen for $20^{\circ} \mathrm{C}$. Every other curve was shifted into the right direction with the right shift factor. From the master curve (cf. Figure 6) one can observe the change of the storage moduli versus the time in logarithmic scale.

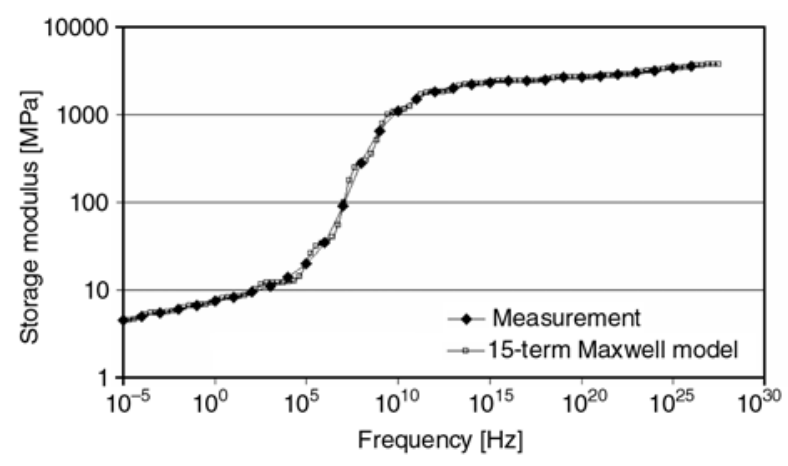

Figure 6. Storage moduli master curve of the EPDM rubber; reference temperature $T_{r e f}=20^{\circ} \mathrm{C}$
Table 1. Parameters of the fitted 15-term Maxwell-model

\begin{tabular}{|c|c|c|c|}
\hline $\mathbf{E}_{\mathbf{0}}[\mathbf{M P a}]$ & $\mathbf{3 . 7 \cdot 1 0 ^ { + \mathbf { 0 3 } }}$ & $\mathbf{E}_{\boldsymbol{\infty}}[\mathbf{M P a}]$ & $\mathbf{4 . 5} \cdot \mathbf{1 0}^{+\mathbf{0 0}}$ \\
\hline \multicolumn{2}{|c|}{$\mathbf{t}[\mathbf{s e c}]$} & \multicolumn{2}{c|}{ Coefficients } \\
\hline$t(1)$ & $1.61 \cdot 10^{+03}$ & $e(1)$ & $2.83 \cdot 10^{-04}$ \\
\hline$t(2)$ & $1.29 \cdot 10^{+01}$ & $e(2)$ & $3.12 \cdot 10^{-04}$ \\
\hline$t(3)$ & $1.53 \cdot 10^{-01}$ & $e(3)$ & $4.45 \cdot 10^{-04}$ \\
\hline$t(4)$ & $9.89 \cdot 10^{-04}$ & $e(4)$ & $1.03 \cdot 10^{-03}$ \\
\hline$t(5)$ & $1.18 \cdot 10^{-06}$ & $e(5)$ & $6.09 \cdot 10^{-03}$ \\
\hline$t(6)$ & $8.51 \cdot 10^{-09}$ & $e(6)$ & $6.74 \cdot 10^{-02}$ \\
\hline$t(7)$ & $1.42 \cdot 10^{-10}$ & $e(7)$ & $2.22 \cdot 10^{-01}$ \\
\hline$t(8)$ & $1.80 \cdot 10^{-12}$ & $e(8)$ & $1.90 \cdot 10^{-01}$ \\
\hline$t(9)$ & $1.27 \cdot 10^{-14}$ & $e(9)$ & $1.12 \cdot 10^{-01}$ \\
\hline$t(10)$ & $2.00 \cdot 10^{-16}$ & $e(10)$ & $5.07 \cdot 10^{-02}$ \\
\hline$t(11)$ & $1.10 \cdot 10^{-19}$ & $e(11)$ & $6.91 \cdot 10^{-02}$ \\
\hline$t(12)$ & $1.38 \cdot 10^{-22}$ & $e(12)$ & $4.59 \cdot 10^{-02}$ \\
\hline$t(13)$ & $1.62 \cdot 10^{-24}$ & $e(13)$ & $8.62 \cdot 10^{-02}$ \\
\hline$t(14)$ & $6.62 \cdot 10^{-26}$ & $e(14)$ & $6.76 \cdot 10^{-02}$ \\
\hline$t(15)$ & $1.82 \cdot 10^{-27}$ & $e(15)$ & $7.87 \cdot 10^{-02}$ \\
\hline
\end{tabular}

The mathematical description of the viscoelastic material behaviour is a complex task. With the help of the ViscoData software [16] we have fitted a 15-term Maxwell-model to the measured storage moduli master curve [17-19]. The detailed description of the Maxwell-parameter optimization is described in ref. [16]. The parameters of the Maxwell-model are summarized in Table 1. The storage modulus master curve of the DTMA measurements and the fitted master curve of the 15-term Maxwell-model can be seen in Figure 6. The listed Maxwell-parameters in Table 1 (relaxation time $(t)$ and dimensionless elastic moduli (coefficients of each Maxwell-element) are formulated specifically for the MSC.Marc FE software.

During the FE-simulation the 15-term Maxwellmodel was combined with a two parameter MoneyRivlin material model. According to the MSC.Marc software the constants of the two term MooneyRivlin material law were calculated from the Young's modulus of the material measured at $-100^{\circ} \mathrm{C}$ (see $E_{0}$ in Table 1) using Equations (16) and (17) $[20,21]$ :

$$
\begin{aligned}
& E=6\left(C_{10}+C_{01}\right) \\
& 4=\frac{C_{10}}{C_{01}}
\end{aligned}
$$

where, $C_{10}$-is the first Mooney-Rivlin parameter, $C_{01}$ - is the second Mooney-Rivlin parameter, $E-$ is Young's modulus. 
Adjusted to the formulation of the FE software, the Mooney-Rivlin parameters were calculated based on the highest modulus of the EPDM rubber material. Using Equations (16) and (17), the calculated Mooney-Rivlin constants are the following:

$C_{10}=123 \mathrm{MPa}$, $C_{01}=493 \mathrm{MPa}$.

\subsection{FE simulation of the rolling friction test}

The model used in the simulation is shown in Figure 7 . The rubber plate was defined as deformable body; the sphere was defined as a rigid body.

The dimension for the rubber plate is $37.6 \mathrm{~mm} \times$ $27.4 \mathrm{~mm} \times 4 \mathrm{~mm}$, divided into 4256 elements $(38 \times 28 \times 4)$. To increase the accuracy of the simulation and to decrease the computing time at the same time, the so called LOCAL ADAPTIVITY of MESH ADAPTIVITY was turned on, which was applied only to the deeper color elements shown in Figure 7. This method increases the number of elements in the chosen region when a given mean strain energy density was reached. In our case this value was $1.5 \mathrm{~N} / \mathrm{mm}^{2}$. In that way the mesh will be changed during the simulation. The original and the automatically modified mesh can be seen in Figure 7. The first picture shows the rubber plate and the rigid sphere in its starting position. The second picture (front view) shows the sphere and rubber plate pushed together (the upper sphere mesh represents the original position of the sphere). The third picture shows the position of the sphere at $t=T / 2$, where the re-meshed part of the rubber plate is also visible.

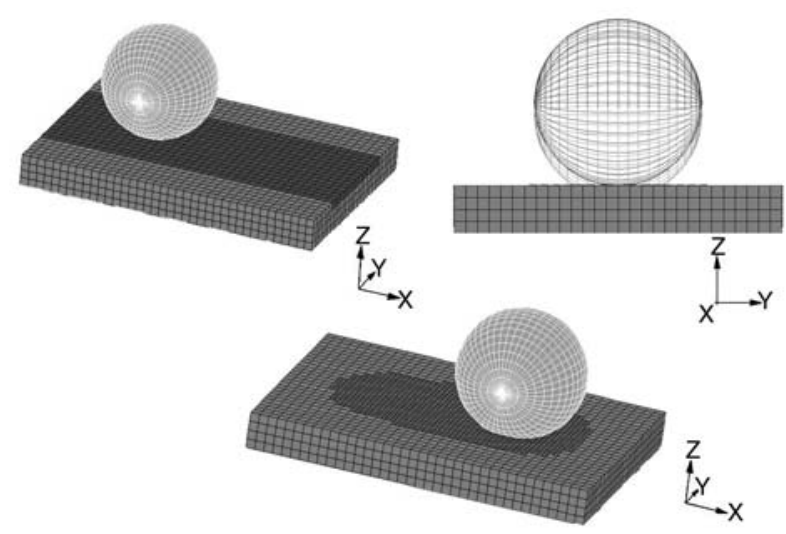

Figure 7. FE model at $t=0$ and at $t=T / 2$ for the Oscillating-RBOP friction simulation
The model was built up from 8-node solid Hermann type elements. There was no friction applied between the rigid sphere and the rubber plate. A rigid flat surface was fixed onto the bottom of the rubber plate. This rigid surface and the bottom of the rubber plate were glued together.

The load was applied by the prescribed displacement of the ball. The ball moved vertically $(-z$ direction, cf. Figure 7) till a fixed position and pressed onto the rubber plate. The horizontal movement (prescribed velocity in direction $x$, cf. Figure 7) was applied to the rigid surface which was glued to the bottom of the rubber plate. Parallel to this horizontal reciprocating motion, an angular velocity was applied onto the rigid sphere. The driving time curves of the prescribed displacements and velocities are summarized in Figure 8. The time curve for the vertical movement of the rigid sphere (tc1) is linear. At $t=0 \mathrm{~s}$ the value of the curve is zero. Subsequently it increases linearly until $t=1 \mathrm{~s}$, where it will be 1 . After this the value remains constant until the end of the cycle $(t=$ $31 \mathrm{~s})$. To ensure a normal force of $140 \mathrm{~N}$, this value (1) will be multiplied with a proper displacement value $(1 \mathrm{~mm})$. The movement of the rigid surface at the bottom of the rubber plate and the angular velocity of the sphere can be driven by the same time curve (tc2). To prescribe the right velocity and right angular velocity, the values of the sinusoidal time curve will be multiplied by $1.47 \mathrm{~mm} / \mathrm{s}$ for the horizontal velocity of the rubber plate, and by $0.21 \mathrm{rad} / \mathrm{s}$ for the angular velocity of the sphere. The value of the sinusoidal time curve (tc2) is zero from $t=0 \mathrm{~s}$ to $t=1 \mathrm{~s}$. In this way, the velocity of the rubber plate will be (Equation (18)):

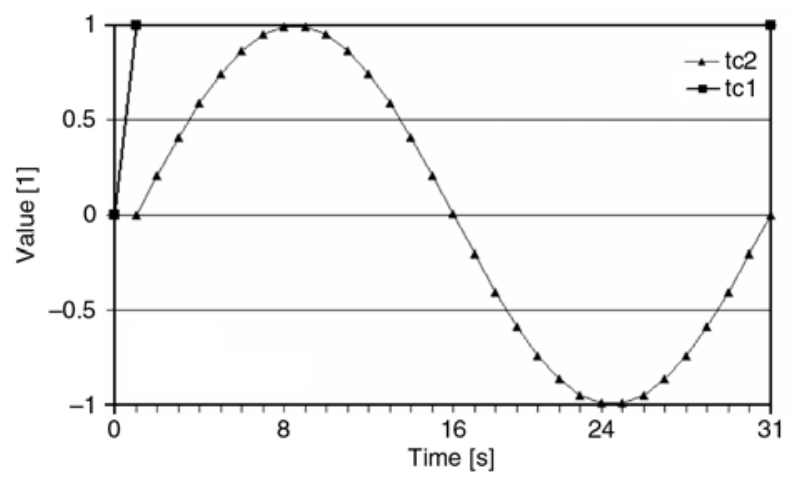

Figure 8. The driving time curves for the vertical displacement of the sphere (tc1), for the horizontal velocity of the rubber plate (tc2) and for the angular velocity of the sphere (tc2) 


$$
v(t)=1.47 \sin \left(\frac{\pi}{15}(t-1)\right) \quad\left[\frac{\mathrm{mm}}{\mathrm{s}}\right]
$$

while the angular velocity of the sphere can be described with Equation (19):

$\omega(t)=0.21 \sin \left(\frac{\pi}{15}(t-1)\right) \quad\left[\frac{\mathrm{rad}}{\mathrm{s}}\right]$

if $1 \mathrm{~s} \leq t \leq 31 \mathrm{~s}$.

\section{Results of the simulation}

Friction force, normal load and the calculated COF from the simulation are shown in Figure 9. The FEcalculated reaction force in vertical $(z)$ direction at the rigid sphere (cf. Figure 7) is defined as the normal force. The friction or tangential force is the reaction force in $x$-direction (cf. Figure 7) which is calculated at the rigid surface gluing to the rubber plate. One can see in Figure 9 that the direction of the friction force was reversed when the ball moved back and COF shows clear oscillating characteristic. The COF was calculated using Equation (11).

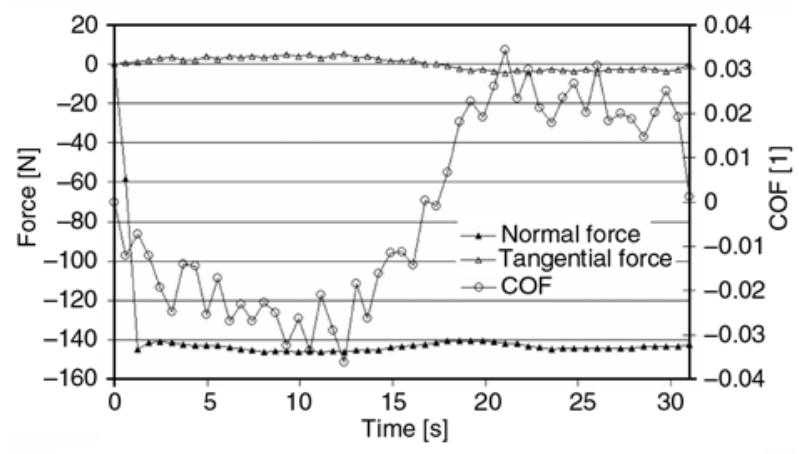

Figure 9. Friction force, normal force and coefficient of friction (COF) calculated by FE simulation

\section{Comparison of the measured and the FE simulated results}

The measured and FE-calculated friction and normal forces are displayed in Figure 10. The curves from the simulation show a fair agreement with the experimental ones. It means that the FE simulation is usable to analyze the rolling process on the rubber plate and get a well quantitative description of the rolling friction.

A more spectacular comparison is the collation of the measured and FE-simulated COF results (cf. Figure 11). Although the measured and the FE cal-

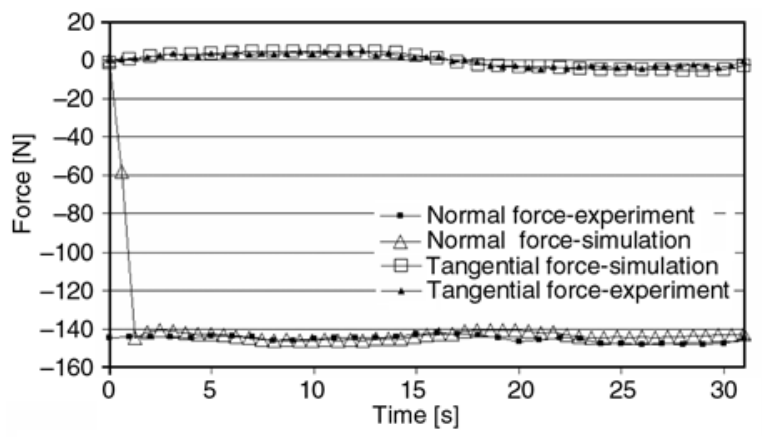

Figure 10. Comparison of friction force and normal loads between experiment and simulation in one cycle

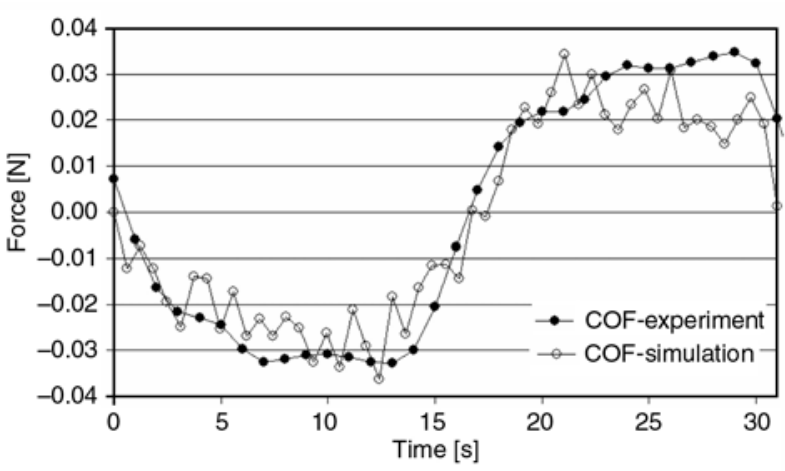

Figure 11. Comparison of COF between experiment and simulation in one cycle

culated values don't cover each other perfectly, the difference between the results is very small. One explanation may relate to the assumption of pure rolling, because in the contact area the micro-slip phenomenon [22] produces stick-slip around the pure rolling lines. At the same time, under lubricated conditions, this effect is not dominant.

\section{Conclusions}

This study describes a general method on how to consider the viscoelastic behavior of rubber materials. The description of the viscoelastic material behavior can be realized, for example, with proper number of Maxwell elements, by which the simulation results can well be adjusted to those of the experiments. Increasing number of elements in the FE-model and/or increasing number of steps during the simulation may further improve the accuracy of the calculations. However, both of the listed refinements can lead to a pronounced increase of the CPU time. Based on the results presented in this work the following conclusions can be made: 
- The viscoelasticity of the EPDM material was determined by DMTA measurements successfully.

- The fitted 15-term Maxwell-model is able to describe the viscoelastic behavior of the investigated EPDM rubber.

- The FE method used is powerful tool to consider the viscoelastic properties of rubbery materials accordingly and to simulate their process of rolling friction.

\section{Acknowledgements}

One of the authors, namely Tibor Goda, is a grantee of the János Bolyai Research Scholarship of the Hungarian Academy of Sciences. This work was performed in the framework of an integrated project of EU (KRISTAL; Contract Nr.: NMP3-CT-2005-515837; www.kristal-project.org).

\section{References}

[1] Tabor D.: The mechanism of rolling friction II. The elastic range. Proceedings of the Royal Society of London, Series A: Mathematical and Physical Sciences, 229, 198-220 (1955).

[2] Flom D. G., Bueche A. M.: Theory of rolling friction for spheres. Journal of Applied Physics, 30, 17251730 (1959).

[3] May W. D., Morris E. L., Atack D.: Rolling friction of a hard cylinder over a viscoelastic material. Journal of Applied Physics, 30, 1713-1724 (1959).

[4] Morland L. W.: Exact solutions for rolling contact between viscoelastic cylinders. The Quarterly Journal of Mechanics and Applied Mathematics, 20, 73-106 (1966).

[5] Knothe K., Wang G.: Zur Theorie der Rollreibung zylindrischer Kunststoffräder. Konstruktion, 41, 193200 (1989).

[6] Morland L. W.: A plane problem of rolling contact in linear viscoelasticity theory. Journal of Applied Mechanics, 29, 345-352 (1962).

[7] Severin D., Lütkebohle H.: Rollreibung zylindrischer Laufräder aus Kunststoff. Konstruktion, 37, 177-184 (1985).
[8] Severin D., Kühlken B.: Tragfähigkeit von Kunststoffrädern unter Berücksichtigung der Eigenerwärmung Teil 1. Konstruktion, 43, 65-71 (1991).

[9] Severin D., Kühlken B.: Tragfähigkeit von Kunststoffrädern unter Berücksichtigung der Eigenerwärmung Teil 2. Konstruktion, 43, 153-160 (1991).

[10] Kulkarni S. M., Rubin C. A., Hahn G. T.: Elasto-plastic coupled temperature-displacement finite element analysis of two-dimensional rolling-sliding contact with a translating heat source. Journal of Tribology, 113, 93-101 (1991).

[11] Severin D., Qiao L.: The thermomechanical calculation of polymer roller with finite element method. in 'Advances in Computational Methods for Simulation' (ed.: Topping B. V. H.) Civil-Comp Press, Edinburgh 73-77 (1996).

[12] Bederna C., Engst W.: Analyse des Eindrück-Rollwiderstandes bei Gurtförderern mit der Methode der Finiten Elemente. Kautschuk und Gummi, Kunststoffe, 51, 690-699 (1998).

[13] Karger-Kocsis J., Mousa A., Major Z., Békési N.: Dry friction and sliding wear of EPDM rubbers against steel as a function of carbon black content. Wear, 264, 359-367 (2008).

[14] Komalan C., George K. E., Kumar P. A. S., Varughese K. T., Thomas S.: Dynamic mechanical analysis of binary and ternary polymer blends based on nylon copolymer/EPDM rubber and EPM grafted maleic anhydride compatibilizer. Express Polymer Letters, 1, 641-653 (2007).

[15] Ferry J. D.: Viscoelastic properties of polymers. John Wiley and Sons, New York (1971).

[16] http://www.viscodata.de/ - accessed June 2007.

[17] Aklonis J. J., MacKnight W. J.: Introduction to polymer viscoelasticity. Wiley Interscience Publication, New York (1983).

[18] Ward I. M.: Mechanical properties of solid polymers. John Wiley and Sons, Chichester (1971).

[19] Tschoegl N. W.: The phenomenological theory of linear viscoelastic behavior. Springer-Verlag, Berlin (1989).

[20] MSC Software Corporation: MSC.MARC Poroduct documentation, Help Volume A: Theory of user information, Version 2001 (2001).

[21] Treloar L. R. G.: The physics of rubber elasticity. Oxford University Press, London (1975).

[22] Johnson K. L.: Contact mechanics. Cambridge University Press, London (1985). 